\title{
O que significa alfabetização ou letramento para os pesquisadores da educação científica e qual o impacto desses conceitos no ensino de ciências
}

\author{
What does alphabetization and literacy mean for science \\ education researchers and what is the impact \\ of these concepts in science teaching
}

Rodrigo Bastos Cunha ${ }^{1}$

\begin{abstract}
Resumo: Este artigo aborda dois grupos distintos de estudos do campo da educação científica e do ensino de ciências que se apropriam de conceitos dos estudos da linguagem e do ensino de línguas, um que trata de alfabetização científica e outro que trata de letramento científico. O principal objetivo é identificar o que há em comum nos estudos desses dois grupos, que noção de alfabetização ou de letramento eles usam, e como esses conceitos influenciam na escolha do que deve ser ensinado na educação científica. Para isso, foram selecionados cinco artigos de cada grupo, publicados em periódicos da área de educação, entre os trabalhos mais influentes, com maior número de citações. Enquanto os que tratam de alfabetização consideram fundamental o ensino de conceitos científicos, os que optam por letramento priorizam, no ensino, a função social das ciências e das tecnologias e o desenvolvimento de atitudes e valores em relação a elas.
\end{abstract}

Palavras-chave: Alfabetização científica. Letramento científico. Ensino de ciências. Linguagem. Ensino de idiomas.

\begin{abstract}
This paper approaches two distinct groups of studies in the field of science education and science teaching that appropriates concepts from language studies and language teaching, ones that deal with scientific alphabetization and other that deals with scientific literacy. The main objective is identify what the studies of these two groups have in common, what notion of alphabetization or literacy they use and how these concepts influence the choice of what should be taught in science education. For that purpose, five papers from each group published in magazines in the educational area were selected, among the most influential works, with the major number of citations. While those which deal with alphabetization consider the teaching of scientific concepts to be fundamental, those who opt for literacy prioritize the social function in the teaching of science and technology and the development of attitudes and values in relation to them.
\end{abstract}

Keywords: Scientific alphabetization. Scientific literacy. Science teaching. Language studies. Languages teaching.

\footnotetext{
${ }^{1}$ Universidade Estadual de Campinas (Unicamp), Instituto de Estudos da Linguagem, Campinas, SP, Brasil.

E-mail: <rbcunha@unicamp.br>.
} 


\section{Introdução}

Um trabalho recente (CUNHA, 2015) sobre a apropriação de conceitos dos estudos da linguagem por pesquisadores do campo do ensino de ciências, compara pesquisas que usam a expressão "alfabetização científica" com pesquisas que optam pelo uso de "letramento científico". Em linhas gerais, embora a amostragem seja pequena e essa questão possa ser melhor investigada com a análise de um universo mais amplo de estudos sobre alfabetização científica e sobre letramento científico, esse trabalho mostra uma tendência significativa de maior inserção em bibliografia dos estudos da linguagem entre os pesquisadores do ensino de ciências que tratam da noção de letramento, além de também ser maior, entre esses autores, a inserção em bibliografia em língua inglesa que trata de scientific literacy ou de temas correlatos.

De acordo com Laugksch (2000, p. 72, tradução nossa), essa associação do termo literacy com o conhecimento produzido nas áreas de ciências apareceu pela primeira vez, provavelmente, no artigo "Science literacy: its meaning for American schools", de Paul Hurd, em 1958, embora a ideia de que o público deveria ter algum conhecimento de ciência já existisse pelo menos desde o início do século XX. Segundo esse autor, o interesse no letramento científico, no final dos anos 1950, estava ligado, por um lado, à preocupação da comunidade científica americana em ter apoio público à ciência para responder ao lançamento do Sputinik pelos soviéticos; por outro lado, ao mesmo tempo, os americanos estavam preocupados se suas crianças estavam recebendo uma educação para capacitá-las a competir em uma sociedade em crescente sofisticação científica e tecnológica.

Santos (2007) observa que a ciência foi incorporada ao currículo escolar, tanto na Europa como nos Estados Unidos a partir do século XIX, enquanto, no Brasil, o ensino de ciências passou a ser efetivamente incorporado ao currículo escolar na década de 1930. Segundo o autor, se nos anos 1950, no contexto da corrida espacial, havia a preocupação em formar novos cientistas, nos anos 1960 e 1970, com o agravamento de problemas ambientais, ganha destaque a preocupação com aspectos sociais relacionados ao modelo de desenvolvimento científico e tecnológico. Santos (2007) diz que sua escolha pelo termo "letramento" busca enfatizar as questões sociais relacionadas às ciências.

De acordo com Soares (2010), no Brasil, o termo "letramento" surgiu no discurso de especialistas da área de estudos da linguagem e ensino de língua, na segunda metade da década de 1980, para distinguir o mero aprendizado da codificação da escrita, a alfabetização, do impacto de seu efetivo uso em práticas sociais. Soares (2010, p. 79) observa que "do ponto de vista histórico e antropológico, é [...] significativo que a língua inglesa tenha incorporado o termo illiteracy (ausência de letramento) muito antes que surgisse o termo literacy (letramento)". O primeiro, segundo ela, já estava dicionarizado desde 1660, enquanto o registro do segundo só aparece no final do século XIX. A autora avalia que o "[...] surgimento de literacy nessa época reflete certamente uma mudança histórica nas práticas sociais: novas demandas sociais de uso da leitura e escrita exigiram uma nova palavra para designá-las. Consequentemente, um novo conceito foi criado" (SOARES, 2010, p. 79).

O mesmo teria acontecido, segundo Soares (2010), quando novas demandas sociais de uso da escrita no Brasil fizeram emergir, nos anos 1980, o termo "letramento".

Ao contrário do termo "alfabetização", que pressupõe um ponto de ruptura entre os que não sabem ler e escrever (analfabetos) e os que sabem (alfabetizados), o termo "letramen- 
to" pressupõe um processo contínuo envolvendo diferentes níveis de complexidade no uso da escrita. Soares (2010, p. 70) diz que "as habilidades de escrita, tal como as de leitura, devem ser aplicadas diferenciadamente à produção de uma variedade de materiais escritos: da simples assinatura do nome ou elaboração de uma lista de compras até a redação de um ensaio ou de uma tese de doutorado". De acordo com ela

[...] as competências que constituem o letramento são distribuídas de maneira contínua, cada ponto ao longo desse contínuo indicando diversos tipos e níveis de habilidades, capacidades e conhecimentos, que podem ser aplicados a diferentes tipos de material escrito. Em outras palavras, o letramento é uma variável contínua, e não discreta ou dicotômica. Portanto, é difícil especificar, de uma maneira não arbitrária, uma linha divisória que separaria o indivíduo letrado do indivíduo iletrado. (SOARES, 2010, p. 70-71, grifos do autor).

A ideia de que há diferentes níveis de complexidade nas atividades de leitura e escrita levou à criação, em 2001, do Indicador Nacional de Alfabetismo Funcional (INAF), um levantamento em larga escala sobre habilidades de leitura e escrita da população brasileira de 15 a 64 anos, realizado pelo Instituto Paulo Montenegro, ligado ao Ibope, em parceria com a Organização Não Governamental (ONG) Ação Educativa. O INAF é dividido em quatro níveis: o primeiro, de analfabetismo, no sentido tradicional de condição dos que não sabem ler e escrever; o segundo, de alfabetismo rudimentar, envolve, por exemplo, a capacidade de localizar informações explícitas em textos muito curtos; o terceiro, de alfabetismo básico, envolve, entre outras coisas, a capacidade de localizar informações em texto de extensão média, mesmo que ela não apareça na mesma forma literal em que é mencionada na pergunta do questionário elaborado para esse levantamento; o quarto, de alfabetismo pleno, envolve a capacidade de ler textos mais longos, relacionar partes do texto, comparar dois textos, realizar inferências e sínteses.

Embora o termo que denomina esse indicador seja "alfabetismo", o título do livro que reúne uma coletânea de textos de pesquisadores das áreas de educação, estudos da linguagem, ensino de línguas e letras, analisando os resultados daquele primeiro levantamento realizado em 2001, é "Letramento no Brasil” (RIBEIRO, 2003). Até 2005, o INAF continuou a ser publicado alternando o levantamento sobre habilidades de leitura e escrita nos anos ímpares (2001, 2003 e 2005) com o levantamento sobre habilidades de cálculo e resolução de problemas nos anos pares (2002 e 2004). Em 2006, a metodologia do levantamento foi aperfeiçoada e a escala de alfabetismo passou a integrar as habilidades de leitura e escrita (letramento) com as de matemática (numeramento). O primeiro levantamento com essas duas dimensões do alfabetismo mensuradas de forma integrada e simultânea foi realizado em 2007. Em 2011, foram publicados dados comparativos sobre todos os levantamentos do INAF realizados nessa primeira década, desde a sua criação, em 2001 (AÇÃO EDUCATIVA, 2011).

Em 2014, a Ação Educativa e o Instituto Paulo Montenegro reuniram-se a uma outra entidade, o Instituto Abramundo, para criar um novo tipo de levantamento, o Indicador de Letramento Científico, "com o objetivo de determinar diferentes níveis de domínio das habilidades de letramento no uso da linguagem e dos conceitos do campo da ciência no cotidiano dos brasileiros" (INSTITUTO ABRAMUNDO, 2014, p. 5). 
No campo de pesquisas em ensino de ciências, no entanto, o termo "letramento" ainda não está muito difundido e predominam, em números absolutos, os trabalhos que tratam de alfabetização científica, embora tenha sido crescente e relevante a contribuição dos pesquisadores que tratam de letramento científico. A análise que se pretende fazer aqui é sobre o que há em comum e o que distingue os trabalhos que tratam de alfabetização científica e os que tratam de letramento científico. Que definição de alfabetização ou de letramento é usada e qual a sua implicação no modelo de ensino de ciências e na escolha do conteúdo a ser ensinado?

\section{Trabalhos que são referência para outros pesquisadores}

Como escopo de análise, foram selecionados apenas artigos publicados em periódicos, entre os trabalhos acadêmicos com maior número de citações que aparecem como resultado de busca realizada no Google Acadêmico pelas expressões "alfabetização científica" (no dia 18 de agosto de 2016) e "letramento científico" (no dia 19 de agosto de 2016). Esse critério de seleção exclui da análise, por exemplo, uma dissertação de mestrado de Lorenzetti (2000) que aparece como o segundo trabalho mais citado entre os que tratam de alfabetização científica, mas contempla um artigo desse mesmo pesquisador, escrito em co-autoria com seu orientador (LORENZETTT; DELIZOICOV, 2001). A seleção também exclui uma tese de doutorado de Sasseron (2008), mas inclui um artigo dessa autora, publicado no mesmo ano da defesa de sua tese e escrito em co-autoria com sua orientadora (SASSERON; CARVALHO, 2008).

Para tentar abarcar uma maior diversidade de autores, buscou-se evitar a inclusão de mais de um trabalho de um mesmo autor no escopo de análise. Por esse outro critério de seleção, o segundo trabalho mais citado entre os que tratam de letramento científico, de Santos e Mortimer (2001) não entra na análise, já que o primeiro autor daquele trabalho assina sozinho o trabalho com maior número de citações (SANTOS, 2007), e o outro autor daquele segundo artigo mais citado também assina sozinho um dos trabalhos entre os mais citados (MORTIMER, 2002). Esse segundo critério também exclui da seleção outros dois artigos, um publicado em Investigações e Ensino de Ciências, de Sasseron e Carvalho (2011a) e outro publicado em Ciência \& Educação, também de Sasseron e Carvalho (2011b), uma vez que o trabalho de 2008 dessas mesmas autoras tem maior número de citações e foi o escolhido para a análise.

A seleção resultou em cinco artigos que tratam de alfabetização científica e cinco que tratam de letramento científico, todos eles publicados entre 2001 e 2009, com exceção de um artigo publicado na revista Educar, de Penick (1998), o qual é uma tradução de texto publicado originalmente em inglês nos Estados Unidos.

Seguem nos quadros 1 e 2 os trabalhos que são objeto desta análise. 
Quadro 1. Artigos publicados em periódicos entre os trabalhos mais citados na busca por alfabetização científica

\begin{tabular}{|c|c|c|c|}
\hline Autor(es) & Título & Periódico & Ano \\
\hline Attico Chassot & $\begin{array}{l}\text { Alfabetização científica: uma possibilidade } \\
\text { de inclusão social }\end{array}$ & $\begin{array}{l}\text { Revista Brasileira de } \\
\text { Educação }\end{array}$ & 2003 \\
\hline $\begin{array}{l}\text { Lúcia Helena } \\
\text { Sasseron, Anna Maria } \\
\text { Pessoa de Carvalho }\end{array}$ & $\begin{array}{l}\text { Almejando a alfabetização científica no } \\
\text { ensino fundamental: a proposição e a } \\
\text { procura de indicadores do processo }\end{array}$ & $\begin{array}{l}\text { Investigações em } \\
\text { Ensino de Ciências }\end{array}$ & 2008 \\
\hline $\begin{array}{l}\text { Leonir Lorenzetti, } \\
\text { Demétrio Delizoicov }\end{array}$ & $\begin{array}{l}\text { Alfabetização científica no contexto das } \\
\text { séries iniciais }\end{array}$ & $\begin{array}{l}\text { Ensaio: Pesquisa em } \\
\text { Educação em Ciências }\end{array}$ & 2001 \\
\hline $\begin{array}{l}\text { Arlete Terezinha } \\
\text { Esteves Brandi, Célia } \\
\text { Margutti do Amaral } \\
\text { Gurgel }\end{array}$ & $\begin{array}{l}\text { A alfabetização científica e o processo } \\
\text { de ler e escrever em séries iniciais: } \\
\text { emergências de um estudo de } \\
\text { investigação-ação }\end{array}$ & Ciência \& Educação & 2002 \\
\hline John E. Penick & Ensinando alfabetização científica & Educar & 1998 \\
\hline
\end{tabular}

Fonte: Google Acadêmico

Quadro 2. Artigos publicados em periódicos entre os trabalhos mais citados na busca por letramento científico

\begin{tabular}{|l|l|l|l|}
\hline \multicolumn{1}{|c|}{ Autor(es) } & \multicolumn{1}{|c|}{ Título } & \multicolumn{1}{c|}{ Periódico } & Ano \\
\hline $\begin{array}{l}\text { Wildson Luiz Pereira } \\
\text { dos Santos }\end{array}$ & $\begin{array}{l}\text { Educação científica na perspectiva de } \\
\text { letramento como prática social: funções, } \\
\text { princípios e desafios }\end{array}$ & $\begin{array}{l}\text { Revista Brasileira de } \\
\text { Educação }\end{array}$ & 2007 \\
\hline $\begin{array}{l}\text { Eduardo Fleury } \\
\text { Mortimer }\end{array}$ & $\begin{array}{l}\text { Uma agenda para a pesquisa em educação } \\
\text { em ciências }\end{array}$ & $\begin{array}{l}\text { Revista Brasileira } \\
\text { de Pesquisa em } \\
\text { Educação em Ciências }\end{array}$ & 2002 \\
\hline $\begin{array}{l}\text { Carmem Lúcia Costa } \\
\text { Amaral, Eduardo da } \\
\text { Silva Xavier, Maria } \\
\text { de Lourdes Maciel }\end{array}$ & $\begin{array}{l}\text { Abordagem das relações ciência/tecnologia/ } \\
\text { sociedade nos conteúdos de funções } \\
\text { orgânicas em livros didáticos de química do } \\
\text { ensino médio }\end{array}$ & $\begin{array}{l}\text { Investigações em } \\
\text { Ensino de Ciências }\end{array}$ & 2009 \\
\hline $\begin{array}{l}\text { Erika Zimmermann, } \\
\text { Paula Cristina } \\
\text { Queiroz Evangelista }\end{array}$ & $\begin{array}{l}\text { Pedagogos e o ensino de física nas séries } \\
\text { iniciais do ensino fundamental }\end{array}$ & $\begin{array}{l}\text { Caderno Brasileiro de } \\
\text { Ensino de Física }\end{array}$ & 2007 \\
\hline $\begin{array}{l}\text { Adriana Gonçalves } \\
\text { Soares, Francisco } \\
\text { Ângelo Coutinho }\end{array}$ & $\begin{array}{l}\text { Leitura, discussão e produção de textos } \\
\text { como recurso didático para o ensino de } \\
\text { biologia }\end{array}$ & $\begin{array}{l}\text { Revista Brasileira } \\
\text { de Pesquisa em } \\
\text { Educação em Ciências }\end{array}$ & 2009 \\
\hline
\end{tabular}

Fonte: Google Acadêmico. 


\section{O que ensinar: a relação da ciência com a sociedade ou a ciência em si?}

Além de os trabalhos terem em comum o interesse em contribuir para a melhoria do ensino de ciências, tanto os que tratam de alfabetização quanto os que tratam de letramento são influenciados pelas contribuições da sociologia da ciência, particularmente no que diz respeito à abordagem das relações entre ciência, tecnologia, sociedade e meio ambiente. Porém, o espaço que esse enfoque dos impactos da ciência deve ocupar no ensino, em comparação com o espaço a ser dado aos conceitos, termos e processos da ciência, varia de acordo com os valores de cada pesquisador da área de ensino de ciências acerca do conhecimento científico.

Penick (1998), falando sobre as salas de aula dos Estados Unidos, defende que os alunos deveriam sair da escola apreciando e entendendo a natureza das ciências e o seu papel na sociedade. Segundo ele, isso envolve "ensinar as ciências e a tecnologia focalizando os temas sociais, muitos dos quais detêm um aspecto científico ou tecnológico, o que se chama abordagem CTS (ciência/tecnologia/sociedade)" (PENICK, 1998, p. 93). Brandi e Gurgel (2002, p. 123) afirmam que a alfabetização científica nas séries iniciais "é um trabalho cuja primeira ação a empreender será trabalhar na formação de professores a compreensão que possuem sobre suas próprias crenças e valores acerca do enfoque Ciência-Tecnologia-Sociedade/CTS”.

Zimmermann e Evangelista (2007), cujo trabalho é o relato de uma experiência na formação de professores para superar a resistência ao ensino de física nas séries iniciais do ensino fundamental, mencionam que sua disciplina incluía a "função da História da Ciência no ensino de ciências, aprendizagem científica centrada em temas, eventos, problematização e enfoque CTS (Ciência, Tecnologia e Sociedade)" (ZIMMERMANN; EVANGELISTA, 2007, p. 267). Amaral, Xavier e Maciel (2009, p. 102) explicam que uma eficaz associação dos termos Ciência/Tecnologia/Sociedade requer "trabalhar a ciência como atividade humana, historicamente contextualizada, indicando os cenários socioeconômico e cultural onde as descobertas científicas foram ou estão sendo realizadas".

Santos (2007, p. 479) defende a importância da "compreensão do impacto da ciência e da tecnologia sobre a sociedade em uma dimensão voltada para a compreensão pública da ciência dentro do propósito da educação básica de formação para a cidadania”. Segundo esse autor, há dois grandes grupos nos trabalhos que tratam de alfabetização científica e letramento científico: um de categorias relativas à especificidade do conhecimento científico e outro de categorias relativas à função social das ciências. De acordo com Santos (2007, p. 477), se a prioridade do ensino de ciências for preparar novos cientistas, "o enfoque curricular será centrado em conceitos científicos; se o objetivo for voltado para a formação da cidadania, o enfoque englobará a função social e o desenvolvimento de atitudes e valores".

Lorenzetti e Delizoicov (2001, p. 5) afirmam que a alfabetização científica não tem como objetivo "treinar futuros cientistas, ainda que para isso possa contribuir. Objetiva sim, que os assuntos científicos sejam cuidadosamente apresentados, discutidos, compreendendo seus significados e aplicados para o entendimento do mundo”. Essa é uma questão relevante a ser pensada tanto por aqueles que pesquisam na área de ensino de ciências ou trabalham com formação de professores de ciências quanto por aqueles que elaboram materiais didáticos ou atuam em políticas públicas na área de educação: qual conteúdo deve ser selecionado para a formação no ensino básico voltada não apenas para futuros cientistas, mas para cidadãos que podem escolher qualquer campo de atuação? 
De acordo com Sasseron e Carvalho (2008), a alfabetização científica é estruturada em três grandes eixos: o primeiro, voltado à compreensão básica de termos, conhecimentos e conceitos científicos fundamentais; o segundo, voltado para a compreensão da natureza da ciência e dos fatores éticos e políticos que circundam a sua prática; e o terceiro, voltado ao entendimento das relações existentes entre ciência, tecnologia, sociedade e meio-ambiente. Como já apontamos acima, o enfoque nesse terceiro eixo, segundo Santos (2007), seria voltado para a formação da cidadania e o desenvolvimento de atitudes e valores em relação à ciência. Por outro lado, o enfoque nos conceitos científicos e na natureza da ciência, entendida como "um conjunto de elementos que tratam da construção, estabelecimento e organização do conhecimento científico" (MOURA, 2014, p. 32), se não tem como objetivo fundamental a formação de futuros cientistas, pode ser considerado como uma formação cultural acerca das contribuições intelectuais da humanidade, assim como o ensino sobre os clássicos da literatura. Entretanto, autores como Lorenzetti e Delizoicov (2001, p. 5) consideram que "aumentar o nível de entendimento público da ciência é hoje uma necessidade, não só como um prazer intelectual, mas também uma necessidade de sobrevivência do homem”.

Esse é um ponto em comum entre os autores que escolhem o termo "alfabetização" e que merece uma reflexão: essa escolha não apenas supervaloriza o conhecimento científico, mas pressupõe um analfabetismo que poderia até mesmo comprometer, segundo aqueles autores, a sobrevivência dos que estão nessa condição. Sem querer desmerecer a importância do conhecimento científico, a história da humanidade nos ensina que sempre existiram estratégias de sobrevivência, mesmo entre os que não tiveram acesso a uma educação científica ou sequer a qualquer tipo de escolarização formal.

Mortimer (2002, p. 28-29) observa que "muitas pessoas vivem perfeitamente bem sem nunca ter tido acesso a uma cultura científica" e questiona: “em que extensão as pessoas empregam conceitos científicos para tomar decisões na vida cotidiana?" Esse autor considera que "o conhecimento científico é essencial para as decisões que tomamos na vida cotidiana". Mas a questão a ser pensada, quando se trata de ensino de ciências, é a seguinte: qual conhecimento é essencial para todo e qualquer cidadão, dentre todo o arcabouço de conhecimento construído ao longo da história da humanidade?

\section{O que dizem trabalhos em língua inglesa sobre science literacy ou scientific literacy ${ }^{2}$}

Shen (1975, p. 265-267, tradução nossa) distingue três níveis de science literacy, que opto por traduzir aqui como "letramento em ciência". O primeiro, que ele chama de prático, estaria ligado a questões básicas de saúde e alimentação, como a importância do aleitamento materno para a criação de anticorpos em bebês e a redução da mortalidade infantil ou o conhecimento sobre a informação nutricional na escolha de um produto alimentício a ser consumido. O segundo, que ele chama de cívico, envolve o posicionamento do cidadão em relação a políticas

\footnotetext{
${ }^{2}$ Para ver uma maior variedade de autores, Laugksch (2000) é uma boa revisão bibliográfica.
} 
públicas em áreas afetadas pela ciência e pela tecnologia, como energia, transportes, comunicação, entre outras. O terceiro, que ele chama de cultural, envolve a leitura de um artigo sobre genética em uma revista ou a audiência de um programa de televisão sobre astronomia por leigos interessados na ciência como uma expressão cultural da humanidade, assim como poderiam se interessar pela leitura de uma tragédia clássica. Para esse autor, o letramento em ciência, nesses três níveis, envolve não apenas a educação científica formal nas escolas, mas também os meios de comunicação de massa, que atingem cidadãos de qualquer área de atuação e de diferentes níveis de escolaridade.

De acordo com Ayala (1996), não se espera que uma pessoa cientificamente letrada saiba que a expressão do DNA é mediada por uma molécula de RNA transmissor. Para esse autor, ser cientificamente letrado envolve saber que a exploração de recursos naturais não é só benéfica e tampouco só prejudicial, ou que uma decisão política na área de energia pode gerar um benefício social e econômico, mas também um problema ambiental. Esse conhecimento, segundo Ayala, possibilitaria o posicionamento do cidadão em relação a políticas públicas como a construção de uma usina nuclear ou a carvão, por exemplo.

Essa definição do que se esperar de uma pessoa cientificamente letrada, bastante próxima do que Shen (1975) define como sendo próprio do letramento cívico em ciência, pode ser associada aos trabalhos do grupo dos educadores em ciência que, segundo Santos (2007), priorizam no ensino a função social das ciências e das tecnologias e o desenvolvimento de atitudes e valores em relação a elas. Os trabalhos dos autores que tratam de alfabetização científica, aqui analisados, ainda que defendam a abordagem das relações entre ciência, tecnologia e sociedade, o que inclui os impactos da ciência, seus riscos e benefícios, consideram fundamental o ensino de conceitos científicos. Lorenzetti e Delizoicov (2001, p. 7) preconizam que "as escolas, através de seu corpo docente, precisam elaborar estratégias para que os alunos possam entender e aplicar os conceitos científicos básicos nas situações diárias, desenvolvendo hábitos de uma pessoa cientificamente instruída”. Quais seriam os conceitos científicos básicos a serem aplicados em situações diárias? No artigo aqui analisado, esses autores não definem ${ }^{3}$. Situações diárias talvez possam ser associadas não propriamente a conceitos científicos ou teorias, mas a certos conhecimentos práticos, como na definição de letramento em ciência feita por Shen (1975).

A escolha dos pesquisadores de ensino de ciências pelo termo "alfabetização" pressupõe um analfabetismo entre aqueles que não possuem um tipo de conhecimento específico, o científico, o qual é tido, por esses autores, não como mais uma entre outras formas de compreender o mundo que nos rodeia - sem dúvida, a de maior prestígio -, mas a única. Segundo Lorenzetti e Delizoicov (2001, p. 8), a alfabetização científica que eles propõem "preocupa-se com os conhecimentos científicos, e sua respectiva abordagem, que sendo veiculados nas primeiras séries do ensino fundamental, se constituam num aliado para que o aluno possa ler e compreender seu universo". Ao que parece, para esses autores, uma leitura de mundo que não seja a da ciência não é considerada válida e deve ser esquecida do lado de fora da sala de aula.

\footnotetext{
${ }^{3}$ Em sua dissertação de mestrado, Lorenzetti (2000, p. 69; 104) usa duas vezes a expressão "conceitos científicos básicos", uma na página 69 e outra na página 104, em ambas citando outros autores, mas nenhuma delas é seguida de exemplos ou definições do que seriam esses conceitos científicos básicos.
} 
Attico Chassot é o autor com maior número de citações entre os trabalhos sobre alfabetização científica (CHASSOT, 2003). Ele critica o ensino voltado para a memorização de teorias, conceitos e processos científicos como a taxonomia, na biologia, as configurações eletrônicas, na química, ou as fórmulas, na física - tipo de conhecimento, segundo ele, fadado ao esquecimento após as provas de avaliação. Chassot (2003) defende um ensino que mostre não apenas os benefícios da ciência, mas também sua face controversa. No entanto, a sua definição do termo que pressupõe a falta de conhecimento científico reflete a visão de que, para esse autor, esse tipo de conhecimento seria o único válido: "ser alfabetizado cientificamente é saber ler a linguagem em que está escrita a natureza. É um analfabeto científico aquele incapaz de uma leitura do universo" (CHASSOT, 2003, p. 91).

O posicionamento dos autores que tratam de letramento científico, nesse aspecto, é diferente. Soares e Coutinho (2009, p. 4) observam que "a linguagem científica, assim como a linguagem específica de outras áreas, possui recursos lexicogramaticais particulares”, os quais, segundo eles, "codificam conhecimentos, valores e visão de mundo específicos da comunidade científica". Ou seja, trata-se de uma entre várias possíveis visões de mundo. Amaral, Xavier e Maciel (2009, p. 112) alertam: “[...] ao não vincular os conhecimentos científicos com os conhecimentos prévios dos alunos, contribui-se para a construção de uma imagem errônea da ciência, como verdade absoluta, além de tornar-se um obstáculo no processo de apropriação do conhecimento".

A valoração do conhecimento científico como única forma válida de ver o mundo - que chega ao extremo de colocar o analfabetismo como risco à sobrevivência - encontra muita similaridade na valoração que se dá à escrita em relação às variações orais existentes em toda e qualquer língua natural. E isso se reflete nos trabalhos dos autores que tratam de alfabetização científica. Para Sasseron e Carvalho (2008, p. 334), a alfabetização deve "possibilitar ao analfabeto a capacidade de organizar seu pensamento de maneira lógica, além de auxiliar na construção de uma consciência mais crítica em relação ao mundo que o cerca”. É como se, para essas autoras, a escrita proporcionasse um ganho cognitivo em relação a quem não tem acesso a essa modalidade da língua.

\section{O que dizem os estudos da linguagem}

De acordo com Kleiman (1995, p. 23), "a tese das consequências cognitivas da aquisição da escrita pareceria se remontar às efetivas diferenças na resolução de problemas de classificação, categorização, raciocínio dedutivo lógico, entre outros", constatadas em pesquisa realizada na antiga União Soviética no início da década de 1930. Segundo ela, esse estudo não permitia dizer se a variável que determina as diferenças é a aquisição da escrita ou a escolarização, "uma vez que a escola é, em quase todas as sociedades, a principal agência de letramento" (KLEIMAN, 1995, p. 25). A autora menciona um outro estudo, realizado no início dos anos 1980, que isolou essas duas variáveis, comparando grupos com formas distintas de uso da escrita: um usava a escrita da língua vai, adquirida informalmente em contexto familiar; outro usava a escrita em árabe, adquirida formalmente em contexto religioso; e um terceiro usava a escrita em língua inglesa, adquirida formalmente na escola. Kleiman (1995, p. 25) afirma que os resultados da pesquisa “apontam claramente que o tipo de 'habilidade' que é desenvolvido depende da prática 
social em que o sujeito se engaja quando ele usa a escrita". O desenvolvimento de habilidades cognitivas universalmente atribuído à escrita, na verdade, seria "consequência da escolarização, pois foram apenas os sujeitos escolarizados, que conheciam a língua inglesa, os que demonstraram diferenças significativas sistemáticas quanto às formas de resolver tarefas de classificação, categorização, raciocínio lógico dedutivo, memorização" (KLEIMAN, 1995, p. 25-26).

Kleiman (1995, p. 25-26) alerta:

Os problemas da associação da escrita ao desenvolvimento cognitivo são vários. O mais importante talvez seja o fato de que uma vez que os grupos não-letrados ou não-escolarizados são comparados com grupos letrados ou escolarizados, estes últimos podem vir a ser a norma, o esperado, o desejado, principalmente porque os pesquisadores são membros de culturas ocidentais letradas. Quando a comparação é realizada, estamos a um passo de concepções deficitárias de grupos minoritários..., concepções estas perigosas pois podem fornecer argumentos para reproduzir o preconceito, chegando até a criar duas espécies, cognitivamente distintas: os que sabem ler e escrever e os que não sabem.

Kleiman (1995, p. 30) propõe pensar "a aquisição da escrita como um processo que dá continuidade ao desenvolvimento linguístico da criança, substituindo o processo de ruptura" que normalmente acontece na prática escolar. O distanciamento entre a língua oral e a língua escrita devido à especialização e ao funcionamento diferenciado de ambas, segundo a autora, configura uma situação "não de línguas em contato, mas de línguas em conflito. Trata-se de duas modalidades que constituiriam variedades discursivas da mesma língua, sendo que cada uma tem status e prestígio diferentes" (KLEIMAN, 1995, p. 49). O respeito à diversidade linguística, preconizado no modelo de letramento defendido por Kleiman, encontra paralelo no respeito à diversidade cultural e consequente diversidade de visões de mundo que se percebe em autores do campo de pesquisa em ensino de ciências que tratam de letramento científico.

Mortimer (2002, p. 32) observa que "a definição física de calor é apenas uma entre muitas definições que o dicionário traz. Isso aponta para uma origem cultural das concepções alternativas, muito mais do que o resultado da interação do indivíduo com o mundo físico". Para o autor,

[...] parece inútil o esforço em mudar concepções que têm raízes profundas nas nossas formas cotidianas de falar sobre o mundo e que são compartilhadas pelos indivíduos de uma mesma cultura. Suprimir essas concepções alternativas significaria suprimir uma forma de se expressar sobre o mundo que permite a comunicação entre os diferentes grupos de uma mesma cultura. (MORTIMER, 2002, p. 32).

Santos (2007, p. 479) considera importante diferenciar alfabetização de letramento, pois segundo ele, "na tradição escolar, a alfabetização científica tem sido considerada na acepção do domínio da linguagem científica", enquanto o letramento científico estaria ligado ao uso do conhecimento científico na prática social. Ao empregar o termo letramento, Santos busca 
"enfatizar a função social da educação científica". Essa ênfase nas práticas sociais de uso do conhecimento científico se reflete em sua definição do que seria uma pessoa letrada em ciência e tecnologia: ela saberia, por exemplo, preparar adequadamente diluições de produtos de limpeza doméstica;

[...] compreender satisfatoriamente as especificações de uma bula de medicamento; adotar profilaxia para evitar doenças básicas que afetam a saúde pública; exigir mercadorias que atendam às exigências legais de comercialização, como especificação de sua data de validade, cuidados técnicos de manuseio, indicação dos componentes ativos; operar produtos eletroeletrônicos (SANTOS, 2007, p. 480).

Os autores do campo de pesquisa em ensino de ciências dos dois grupos aqui analisados têm em comum a visão do conhecimento científico como algo fundamental para a resolução de problemas. O diferencial dos que optam por tratar de letramento científico está não apenas nos exemplos acima de práticas sociais de uso do conhecimento científico na vida cotidiana, mas também na escolha de problemas sociais que podem ser objeto de estudo no ensino de ciências. Mortimer (2002, p. 29) exemplifica:

Se andarmos pelo bairro em que fica uma escola da periferia poderemos constatar que existem uma infinidade de problemas na comunidade que poderiam ser abordados nas classes de ciências, por exemplo, problemas de saneamento básico ou problemas ambientais. Se a escola é perto de uma favela, muitas vezes há esgoto a céu aberto, ou um rio poluído pelo esgoto. Em outras áreas, os moradores jogam lixo na rua. Nesse sentido, não há porque reproduzirmos aqui a prática de colocar os alunos para desemprenharem diferentes papéis na simulação da tomada de decisão sobre problemas hipotéticos. Nós temos problemas demais na vida real para ficarmos simulando problemas hipotéticos.

\section{Considerações finais}

Tem-se discutido muito, já há um bom tempo, no campo da educação, sobre o ensino conteudista ${ }^{4}$, focado em acúmulo de conhecimento, herança do Iluminismo, período em que ganharam destaque as enciclopédias, compêndios de toda contribuição intelectual da humanidade. A análise dos artigos de pesquisadores do ensino de ciências, selecionados entre os trabalhos mais citados que tratam de alfabetização científica e de letramento científico, mostra um consenso sobre a importância da abordagem das relações entre ciência e sociedade na educação científica. A questão a ser pensada é se essa abordagem deve ser o foco do ensino, o seu ponto

\footnotetext{
${ }^{4}$ Ver, por exemplo, Lelis (2001).
} 
principal - e a análise dos artigos mostra que essa é a prioridade nos trabalhos que tratam de letramento científico -, ou algo a mais a ser ensinado além do conhecimento tradicional voltado para categorizações, fórmulas e métodos - considerados fundamentais nos trabalhos que tratam de alfabetização científica aqui analisados. E, caso seja (apenas) algo a mais, em que medida o ensino básico, voltado não apenas para a formação de futuros cientistas, mas para cidadãos que queiram atuar em qualquer tipo de atividade, pode abrir mão de parte do conteúdo voltado para conceitos, teorias e métodos científicos para dar espaço às funções sociais das ciências e ao desenvolvimento de atitudes e valores em relação a elas? Ou a ideia é não abrir mão de algo considerado fundamental - como afirmam autores que tratam de alfabetização científica -, e sim acrescentar as questões sociais ao que já é tradicionalmente ensinado?

A análise acima mostra dois diferenciais bastante relevantes nos trabalhos que tratam de letramento científico. O primeiro e, do meu ponto de vista, mais importante, é considerar a ciência como uma dentre várias possíveis formas de ver e compreender o mundo, como uma contribuição cultural como tantas outras, com seus próprios valores. A consequência disso no ensino é crucial: o respeito às raízes culturais dos conhecimentos prévios dos alunos é fundamental para apresentar a eles uma outra representação cultural do universo, a de maior prestígio na sociedade, a ciência; por outro lado, tentar substituir conhecimentos prévios por um considerado o único válido para ver e compreender o mundo pode gerar resistência e distanciamento dos alunos em relação à ciência.

O segundo diferencial dos trabalhos que tratam de letramento é o foco nas práticas sociais. Se, por um lado, o letramento - sem qualquer tipo de adjetivação, como "científico", "político", "digital" - é definido como "um conjunto de práticas sociais que usam a escrita, enquanto sistema simbólico e enquanto tecnologia, em contextos específicos, para objetivos específicos" (KLEIMAN, 1995, p. 19), o letramento científico enfoca as práticas sociais de uso do conhecimento científico, tanto em termos práticos quanto cívicos, no exercício da cidadania na vida cotidiana.

Ao se pensar em uma educação voltada para a formação cidadã, é importante refletir sobre o que seria mais relevante, por exemplo, nas aulas de matemática: explicar matrizes ou ensinar controle financeiro para que as crianças se tornem adultos que saibam organizar melhor seu orçamento familiar? No ensino de biologia, por sua vez, a taxonomia, a classificação de animais e plantas, seria mais relevante para quem não vai atuar futuramente em alguma área das ciências biológicas do que conhecer o quanto ainda resta de cada bioma do território brasileiro, quais as práticas econômicas mais diretamente ligadas ao desmatamento, qual a relação do desmatamento com o aquecimento global? No ensino de física, é necessário conhecer tantas fórmulas ou é possível abrir mão delas e abordar questões como as diferentes formas de gerar energia, seus custos, seus impactos econômicos, sociais e ambientais? No ensino de química, considerando-se que boa parte dos alunos não irá frequentar um laboratório em sua futura atividade profissional, que tipo de conhecimento eles vão poder levar para a vida toda? Em suma, o que vem a ser, de fato, uma educação cidadã? 


\section{Referências}

AÇÃO EDUCATIVA. INAF Brasil 2011: indicador de alfabetismo funcional: principais resultados. Disponível em: <http://www.institutocyrela.com.br/site/arquivos/geral/ informe_resultados_inaf2011_versao-final_12072012b.pdf>. Acesso em: 18 jan. 2018.

AMARAL, C. L. C.; XAVIER, E. S.; MACIEL, M. L. Abordagem das relações ciência/ tecnologia/sociedade nos conteúdos de funções orgânicas em livros didáticos de química do ensino médio. Investigações em Ensino de Ciências, Porto Alegre, v. 14, n. 1, p. 101-114, 2009. Disponível em: < https://www.if.ufrgs.br/cref/ojs/index.php/ienci/article/ view/412/243>. Acesso em: 18 jan; 2018.

AYALA, F. J. Introductory essay: the case for scientific literacy. Paris: Unesco, 1996. (World science report, 1996).

BRANDI, A. T. E.; GURGEL, C. M. A. A alfabetização científica e o processo de ler e escrever em séries iniciais: emergências de um estudo de investigação-ação. Ciência $\boldsymbol{\&}$ Educação, Bauru, v. 8, n. 1, p. 113-125, 2002. Disponível em: < https://doi.org/10.1590/ S1516-73132002000100009>. Acesso em: 18 jan. 2018.

CHASSOT, A. Alfabetização científica: uma possibilidade para a inclusão social. Revista Brasileira de Educação, Rio de Janeiro, n. 22, p. 89-100, 2003. Disponível em: <https:// doi.org/10.1590/S1413-24782003000100009>. Acesso em: 18 jan. 2018.

CUNHA, R. B. Os trabalhos sobre alfabetização e letramento científico: o diálogo com os estudos da linguagem na apropriação de conceitos por pesquisadores do ensino de ciências. In: REUNIÃO ANUAL DA SBPC, 67., 2015, São Carlos.

Anais... Disponível em: <http://www.sbpcnet.org.br/livro/67ra/resumos/ resumos/3874_1f0b7cffbb168400a0649e3057aca8186.pdf>. Acesso em: 18 jan. 2018.

HURD, P. H. Science literacy: its meaning for American schools. Educational Leadership, Alexandria, v. 16, n. 1, p. 13-16, 52, 1958.

INSTITUTO ABRAMUNDO. ILC: indicador de letramento científico: sumário executivo de resultados. São Paulo, 2014.

KLEIMAN, A. Modelos de letramento e as práticas de alfabetização na escola. In: (Org). Os significados do letramento: uma nova perspectiva sobre a prática social da escrita. Campinas: Mercado de Letras, 1995. p. 15-61.

LAUGKSCH, R. Scientific literacy: a conceptual overview. Science Education, Hoboken, v. 84, n. 1, p. 71-94, 2000.

LELIS, I. A. Do ensino de conteúdos aos saberes do professor: mudança de idioma pedagógico? Educação \& Sociedade, Campinas, v. 22, n. 74, p. 43-58, 2001. Disponível em: <https://doi.org/10.1590/S0101-73302001000100004>. Acesso em: 18 jan. 2018.

LORENZETTTI, L. Alfabetização científica no contexto das séries iniciais. Dissertação (Mestrado em Educação) - Universidade Federal de Santa Catarina. Florianópolis, 2000. 
Cunha, R. B.

LORENZETTI, L; DELIZOICOV, D. Alfabetização científica no contexto das séries iniciais. Ensaio: pesquisa em educação em ciências, Belo Horizonte, v. 3, n. 1, p. 1-17, 2001. Disponível em: <http://www.scielo.br/pdf/epec/v3n1/1983-2117-epec-3-01-00045.pdf>. Acesso em: 18 jan. 2018.

MORTIMER, E.F. Uma agenda para a pesquisa em educação em ciências. Revista Brasileira em Educação em Ciências, Belo Horizonte, v. 2, n. 1, p. 36-59, 2002. Disponível em: <https://seer.ufmg.br/index.php/rbpec/article/view/2351/1751>. Acesso em: 18 jan. 2018.

MOURA, B.A. O que é a natureza da ciência e qual sua relação com a história e a filosofia da ciência? Revista Brasileira de História da Ciência, Rio de Janeiro, v. 7, n. 1, p. 32-46, 2014.

PENICK, J. E. Ensinando alfabetização científica. Educar em Revista, Curitiba, n. 14, p. 91-113, 1998. Disponível em: < https://doi.org/10.1590/0104-4060.183>. Acesso em: 18 jan. 2018.

RIBEIRO, V. M. (Org.). Letramento no Brasil: reflexões a partir do INAF 2001. São Paulo: Global, 2003.

SANTOS, W. L. P. Educação científica na perspectiva de letramento como prática social: funções, princípios e desafios. Revista Brasileira de Educação, Rio de Janeiro, v. 12, n. 36, p. 474-550, 2007. Disponível em: <https://doi.org/10.1590/S1413-24782007000300007>. Acesso em: 18 jan. 2018.

SANTOS, W. L. P.; MORTIMER, E. F. Tomada de decisão para ação social responsável no ensino de ciências. Ciência \& Educação, Bauru, v. 7, n. 1, p. 95-111, 2001. Disponível em: <https://doi.org/10.1590/S1516-73132001000100007 >. Acesso em: 18 jan. 2018.

SASSERON, L. H. Alfabetização científica no ensino fundamental: estrutura e indicadores deste processo em sala de aula. $281 \mathrm{f}$. Tese (Doutorado em Educação) Faculdade de Educação, Universidade de São Paulo, São Paulo, 2008.

SASSERON, L. H.; CARVALHO, A. M. P. Almejando a alfabetização científica no ensino fundamental: a proposição e a procura de indicadores do processo. Investigação em Ensino de Ciências, Porto Alegre, v. 13, n. 3, p. 333-352, 2008. Disponível em: <https:// www.if.ufrgs.br/cref/ojs/index.php/ienci/article/view/445/263>. Acesso em: 18 jan. 2018.

- Alfabetização científica: uma revisão bibliográfica. Investigações em Ensino de Ciências, Porto Alegre, v. 16, n. 1, p. 59-77, 2011a. Disponível em: < https://www.if.ufrgs. br/cref/ojs/index.php/ienci/article/view/246/172>. Acesso em: 18 jan. 2018.

Construindo argumentação na sala de aula: a presença do ciclo argumentativo, os indicadores de alfabetização científica e o padrão de Toulmin. Ciência \& Educação, Bauru, v. 17, n. 1, p. 97-114, 2011b. Disponível em: <https://doi.org/10.1590/S151673132011000100007>. Acesso em: 18 jan. 2018.

SHEN, B. S. P. Science literacy. American Scientist, Research Triangle Park, v. 63, n. 3, p. $265-268,1975$. 
SOARES, A. G.; COUTINHO, F. A. Leitura, discussão e produção de textos como recurso didático para o ensino de biologia. Revista Brasileira de Pesquisa em Educação em Ciências, Belo Horizonte, v. 9, n. 2, p. 1-22, 2009. Disponível em: <https://seer.ufmg.br/ index.php/rbpec/article/view/2202/1602>. Acesso em: 18 jan. 2018.

SOARES, M. Letramento: um tema em três gêneros. 4. ed. Belo Horizonte: Autêntica, 2010. ZIMMERMANN, E.; EVANGELISTA, P. C. Q. Pedagogos e o ensino de física nas séries iniciais do ensino fundamental. Caderno Brasileiro de Ensino de Física, Florianópolis, v. 24, n. 2, p. 261-280, 2007. Disponível em: <https://periodicos.ufsc.br/index.php/fisica/ article/view/1092/12756>. Acesso em: 18 jan. 2018. 